\title{
Application of GIS technology on studying the coastal dynamic of Vjosa River Delta (Albania)
}

\author{
Emiriana Xhaferri ${ }^{1}$, Çerçis Durmishi ${ }^{2}$, Agim Sinojmeri $^{2}$, Leonard ALIMETA ${ }^{3}$, \\ ${ }^{1}$ PhD Student, Polytechnic University of Tirana, Albania \\ ${ }^{2}$ Faculty of Geology and Mining, Polytechnic University of Tirana, Albania \\ ${ }^{3}$ ABIESSE, Albania
}

\begin{abstract}
Vjosa River is the most important river of southern Albania, also is one of Europe's wild rivers, with a length of $272 \mathrm{~km}$ and drainage basin of $6706 \mathrm{~km}^{2}$. It sources from the Pindus Mountains in Greece (where it is called Aoös River) and drains in Albanian coast, near to the Narta Lagoon. Delta of Vjosa River with a surface of $317 \mathrm{~km}^{2}$ is characterized by intensive changes of the shoreline, affected by the wave activity of the Adriatic Sea mostly affecting the river mouth and abandoned channels. The geometry and geomorphology of this delta has been conditioned by tectonic orientation of the Panaja and Frakulla neogene molasses hills. Study of the coastal dynamic and geometry changes of the delta mouth has been reconstructed using the information of topographic maps of Albania from existing studies and reports as well as the information extracted from satellite images. The statistical calculation of erosion and depositional are performed using GIS software technology. The studies performed on dynamics, erosion and accumulation, changes of the mouth shapes and coastline movements lead to the conclusion that delta area of Vjosa River is continuously in evolution. During the period from years 1870 to 2016, the interaction of sedimentological and neotectonic processes lead to total accumulation of an area of $21.7 \mathrm{~km}^{2}$, while an erosion surface of $7.5 \mathrm{~km}^{2}$ is developed mostly at the southern river mouth.
\end{abstract}

Keywords: Coastal; Erosion; GIS Application; Vjosa River, Narta Lagoon 